\title{
IR-UV double resonance spectroscopy of xanthine
}

\author{
Michael P. Callahan, Bridgit Crews, Ali Abo-Riziq, Louis Grace, Mattanjah S. de Vries \\ Department of Chemistry and Biochemistry, University of California, Santa Barbara, CA \\ 93106-9510, USA
}

\begin{abstract}
Zsolt Gengeliczki
Institute of Chemistry, Eötvös Loránd University, 1/A Pázmány P. stny. Budapest, Hungary 1117
\end{abstract}

Tiffani M. Holmes, Glake A. Hill

Department of Chemistry, Computational Center for Molecular Structures and Interactions, Jackson State University, Jackson, MS 39217

\begin{abstract}
We present resonant two-photon ionization (R2PI), UV-UV, and IR-UV double resonance spectra of xanthine seeded in a supersonic jet by laser desorption. We show that there is only one tautomer of xanthine which absorbs in the wavelength range of 36700 to $37700 \mathrm{~cm}^{-1}$. The IR-UV double resonance spectrum shows three strong bands at 3444,3485 , and $3501 \mathrm{~cm}^{-1}$, all of which we assign as N-H stretching vibrations. Comparison of the IR-UV double resonance spectrum with frequencies and intensities obtained from density functional theory (DFT) and second order Møller Plesset (MP2) calculations suggests that the observed xanthine is the diketo $\mathrm{N}(7) \mathrm{H}$ tautomer.
\end{abstract}

\section{Introduction}

Oxopurine xanthine serves an important role in purine metabolism. It is an intermediate in nucleic acid degradation, stemming from the oxidative deamination of guanine. ${ }^{1}$ Xanthine is also one of the purines which could have been present on a primitive Earth, possibly being formed in frozen ammonium cyanide solutions as demonstrated by Miyakawa et al. ${ }^{2}$ or delivered exogenously by carbonaceous chondrite meteorites. ${ }^{3,4}$ Previously, we have shown that the photochemistry of guanine-cytosine base pairs structures may have played an important role in the selection of the specific Watson-Crick structure for encoding life's genetic code. ${ }^{5}$ Understanding the stability of the tautomeric forms of xanthine as well as their electronic structure can provide important information towards their biological activity and possibly their involvement in early prebiotic scenarios.

Xanthine can adopt 14 tautomeric forms through either keto-enol transformation or proton exchange on the in-ring nitrogen atoms. In the presence of water, where there is proton migration, xanthine tautomers are likely to undergo transformation more easily. UV and NMR measurements show that xanthine is found mainly as the diketo $\mathrm{N}(7) \mathrm{H}$ tautomer in aqueous solution (see figure 1 for the numbering scheme). ${ }^{6-8}$ However, Xray diffraction experiments show that the sodium salt of xanthine is found mainly as the diketo $\mathrm{N}(9) \mathrm{H}$ tautomer in the solid state. ${ }^{9}$ In addition, there are a number of theoretical papers which describe the tautomeric preference in the gas phase. Civcir studied 
xanthine in the gas phase and found that the most stable tautomers are the diketo $\mathrm{N}(7) \mathrm{H}$ and $\mathrm{N}(9) \mathrm{H}$ forms based on AM1 and PM3 semi-empirical methods. ${ }^{10}$ Recently, BerdysKochańska et al. concluded that xanthine primarily exists as the diketo $\mathrm{N}(7) \mathrm{H}$ form based on single-point CCSD energies at the MP2 stationary point structures. ${ }^{11}$ The authors also stated that two other tautomers could exist in smaller amounts in the gas phase - the enol 1,7,10 form (ca. $8.0 \mathrm{kcal} / \mathrm{mole}$ higher) and the diketo 1,3,9 form (ca. $8.7 \mathrm{kcal} / \mathrm{mol} \mathrm{higher).}$

Gas phase laser spectroscopy provides a means to study these tautomers, free of a solvent environment, so that their intrinsic properties can be determined. Other purines such as guanine ${ }^{12-14}$ and adenine ${ }^{15-17}$ have been studied extensively by this method; however, to our knowledge, no experimental evidence concerning the tautomeric preference of xanthine in the gas phase exists.

In this paper, we report the one-color R2PI spectrum of xanthine as well as the UV-UV and IR-UV double resonance spectra. UV-UV double resonance spectroscopy determines the number of tautomers measured in the R2PI spectrum. IR-UV double resonance spectroscopy provides tautomer-selected IR spectra in the region of the N-H and $\mathrm{O}-\mathrm{H}$ stretching vibrations. By comparing IR-UV double resonance spectra to frequencies and intensities obtained from density functional theory (DFT) and perturbation theory calculations, we can determine which tautomers are stable in the gas phase.

\section{Experimental Methods}

Xanthine (2,6-dihydroxypurine) was obtained from Sigma-Aldrich and used without further purification. The experimental setup has been described in detail elsewhere $^{18}$ so a brief description will suffice. We laser desorb a thin layer of xanthine from a graphite substrate in front of a pulsed nozzle. The desorption laser, a Nd:YAG (Quantel YG660A) operating at $1064 \mathrm{~nm}$, is attenuated to $1 \mathrm{~mJ} \mathrm{~cm}^{-2}$ and focused to a spot approximately $0.5 \mathrm{~mm}$ diameter within $2 \mathrm{~mm}$ in front of the nozzle orifice. We translate the sample in order to expose fresh sample to successive laser shots. The nozzle consists of a pulsed valve with a nozzle diameter of $1 \mathrm{~mm}$ and a backing pressure of about $6 \mathrm{~atm}$ of argon drive gas. The neutral molecules are skimmed and then ionized with a frequency-doubled dye laser (with Coumarin 540A dye). We detect the ions in a reflectron time-of-flight mass spectrometer. Typical mass resolution $(\mathrm{m} / \Delta \mathrm{m})$ measured at the xanthine peak is 700 or better.

We obtain resonant two-photon ionization (R2PI) spectra by monitoring mass selected peaks while tuning the one-color, two-photon ionization wavelength. We measure UV-UV double resonance spectra with two laser pulses separated in time by 200 ns. Ionization laser intensities are approximately $3 \mathrm{~mJ}$ pulse ${ }^{-1}$ and are strongly attenuated to avoid saturation. The first pulse serves as a "burn" pulse, which removes the ground state population and causes depletion in the ion signal of the second "probe" pulse, provided both lasers are tuned to a resonance of the same tautomer.

IR-UV double resonance spectra are obtained in an analogous way with the burn laser operating in the near-IR region. IR frequencies are produced in an OPO setup (LaserVision) pumped by a Nd:YAG laser operating at its fundamental frequency. 
For this work, we operated within the range of $3250-3740 \mathrm{~cm}^{-1}$, which encompasses NH and $\mathrm{OH}$ modes. Typical IR intensities in the burn region are $12 \mathrm{~mJ} \mathrm{pulse}^{-1}$ and the bandwidth is $3 \mathrm{~cm}^{-1}$.

\section{Theoretical Methods}

The tautomeric equilibria of xanthine were assessed using the Gaussian $03^{19}$ quantum code package. Application of Density Functional Theory's B3LYP hybrid functional (a parameterized combination of Becke's exchange functional, the Lee, Yang, and Parr correlation functional and the exact exchange functional $)^{20-22}$ and Møller Plesset's perturbation (MP2) method ${ }^{23-28}$ with the 6-31G(d,p) and 6-31G(d) basis sets, respectively, yielded equilibrium geometries of the fourteen tautomers of xanthine. We performed second derivative calculations for purposes of vibrational frequency analysis and to verify that the geometries for all species corresponded to local minima. A corrective vibrational scaling factor of 0.9613 to B3LYP calculated frequencies and 0.9422 to MP2 frequencies were applied to account for some anharmonicity ${ }^{29,30}$

The seven lowest energy tautomers along with the predicted relative energies are shown in Figure 1. Figure 1 also shows the numbering scheme for the xanthine tautomers. The numbers for each xanthine tautomer refer to the positions of the hydrogen atoms on the molecule. To provide a more confident assignment of the experimentally recorded spectra, the equilibrium geometries of the two lowest energy tautomers were reoptimized with tighter convergence criteria at the B3LYP/6-311+G(2d,p $)^{31,32}$ level, and the vibrational frequencies were computed on an ultrafine grid. More accurate relative energies of the same two tautomers were predicted with the G3 composite method ${ }^{33}$.

\section{Results and Discussion}

We measured the one-color R2PI spectrum for xanthine in the region of 35715 to $37735 \mathrm{~cm}^{-1}$. Figure 2 shows the R2PI spectrum (bottom trace), displaying only the section exhibiting peaks. The red-most peak appears at $36733 \mathrm{~cm}^{-1}$ with a second intense peak within $8 \mathrm{~cm}^{-1}$. Xanthine has a relatively high ionization potential of $8.89 \pm 0.03 \mathrm{eV}$, as determined by photoelectron spectroscopy (PES). ${ }^{34}$ With such high ionization potentials, we may not be able to observe the $\mathrm{S}_{1} \leftarrow \mathrm{S}_{0}$ origin transition by one-color R2PI. However, this appears unlikely. Previous experiments by Kim et al. ${ }^{35}$ studying gas phase hydration of nucleobases in a supersonic jet showed that their measured ionization potentials for adenine and thymine monomers are nearly identical to those measured with PES. We scanned more than $700 \mathrm{~cm}^{-1}$ from the red-most peak of xanthine and found no other peaks despite being above its ionization potential as determined by PES.

The UV-UV double resonance spectrum, also shown in figure 2 (top trace), shows that only one tautomer is observed under the conditions of our experiment since all the peaks in the R2PI spectrum are accounted for in the UV-UV double resonance spectrum. The probe laser was set to $36741 \mathrm{~cm}^{-1}$ while the burn laser was scanned to record the UVUV double resonance spectrum. However, since the 2 most intense R2PI peaks are separated only by $8 \mathrm{~cm}^{-1}$, we must consider the possibility that the intense "burn" laser could be broad enough to depopulate two tautomers instead of one (if each peak belongs 
to a separate $\mathrm{S}_{1} \leftarrow \mathrm{S}_{0}$ origin transition). To rule this out, we recorded another UV-UV double resonance spectrum at a different probe frequency of $37333 \mathrm{~cm}^{-1}$, which resulted in the same UV-UV spectrum. Additionally, when we recorded IR-UV double resonance spectra, we set the UV probe laser on the 2 most intense R2PI peaks as well as on their peak shoulders. The resulting IR-UV double resonance spectra were all identical. All of these observations lead us to the conclusion we are observing only one tautomer under our experimental conditions. Finally, we cannot exclude the possibility of other tautomers: their spectroscopy could be outside the measured region, both in terms of absorption and in terms of ionization potential or they could go undetected because of excited state dynamics, as discussed below.

Figure 3 shows the IR-UV double resonance spectrum (top trace) of xanthine measured with the R2PI laser set at $36741 \mathrm{~cm}^{-1}$ and the IR scanned from 3250 to 3740 $\mathrm{cm}^{-1}$. This tautomer specific IR spectrum shows 3 strong bands at 3444, 3485, and 3501 $\mathrm{cm}^{-1}$. In table 1 , the calculated vibrational frequencies for the 5 lowest energy tautomers of xanthine are summarized. The MP2/6-31G(d) calculated frequencies exhibit an ordering of peaks comparable to the experimental values of the diketo $\mathrm{N}(7) \mathrm{H}$ and $\mathrm{N}(9) \mathrm{H}$ tautomers. However, the calculated frequencies seem to underestimate the experimental values, which is expected since MP2 frequency calculations tend to give large RMS values causing a shift in frequencies. ${ }^{30}$

The DFT calculations seem to be a much better fit to the experimental IR spectrum compared to the MP2 calculations. Here, the IR frequencies for the $\mathrm{O}-\mathrm{H}$ stretching vibrations are calculated to be $3594 \mathrm{~cm}^{-1}$ or higher for the DFT calculations. Therefore, 12 of the 14 tautomers, those which contain at least one $\mathrm{OH}$ group, can be eliminated as candidate structures. The remaining two candidate structures are the diketo $\mathrm{N}(7) \mathrm{H}$ and $\mathrm{N}(9) \mathrm{H}$ tautomers.

Although both the DFT and ab initio approaches predict the diketo $\mathrm{N}(7) \mathrm{H}$ tautomer to be the most stable one, the calculated frequencies make the assignment of the IR-UV spectra ambiguous. To establish a firm assignment, the two lowest energy tautomers (diketo $\mathrm{N}(7) \mathrm{H}$ and diketo $\mathrm{N}(9) \mathrm{H}$ ) were re-optimized at the B3LYP/6$311+\mathrm{G}(2 \mathrm{~d}, \mathrm{p})$ level with tighter convergence criteria and frequency calculations were repeated on an ultrafine grid. The calculated frequencies were scaled by a factor of $0.9618^{36}$ and are shown as stick spectra in figure 3. In addition, the relative energies of the two lowest tautomers of xanthine were computed with the G3 composite method. The obtained energy difference of $8.7 \mathrm{kcal} / \mathrm{mol}$ supports the lower level DFT and $a b$ initio results and suggests that the diketo $\mathrm{N}(7) \mathrm{H}$ is the most stable tautomer, indeed.

By comparing the gas phase IR spectrum to the calculated frequencies and intensities at the B3LYP/6-311+G(2d,p) level and based on the large energy difference between the two diketo tautomers, we conclude that the diketo $\mathrm{N}(7) \mathrm{H}$ tautomer of xanthine is most likely the one observed in the supersonic jet. The 3 strong bands at 3444,3485 , and $3501 \mathrm{~cm}^{-1}$ in the experimental IR-UV double resonance spectrum can be assigned as the $\mathrm{N} 1 \mathrm{H}, \mathrm{N} 3 \mathrm{H}$, and $\mathrm{N} 7 \mathrm{H}$ stretching vibrations respectively from the normal mode analysis provided by DFT frequency calculations. This assignment is consistent with IR-UV double resonance data on tautomerically blocked xanthine derivatives, shown in Figure 4. A detailed account of their spectroscopy will be published elsewhere. Although the structural difference is very slight, the calculated N-H stretching vibration at $3497 \mathrm{~cm}^{-1}$ belonging to the diketo $\mathrm{N}(9) \mathrm{H}$ tautomer is much less intense than what is 
experimentally observed. More importantly, the peaks at 3497 and $3502 \mathrm{~cm}^{-1}$ for the diketo $\mathrm{N}(9) \mathrm{H}$ tautomer are spaced more closely together. The possibility of the spectrum being due to overlapping contributions of both $\mathrm{N}(7) \mathrm{H}$ and $\mathrm{N}(9) \mathrm{H}$ tautomers is unlikely, both because of the UV-UV and IR-UV results and based on the frequency intensities of the IR-UV double resonance spectrum.

The spectral observation of tautomers in purines and pyrimidines is complicated by tautomer dependent excited state lifetimes, $\tau^{*} .{ }^{37,38}$ The same is true for DNA base cluster structures. ${ }^{39}$ A sub picosecond $\tau^{*}$ can reduce R2PI efficiency when ionizing with nanosecond laser pulses. As a result selected tautomers defy detection. In the case of guanine, for example, the lowest energy tautomer, the $9 \mathrm{H}$ keto, is present in the molecular beam but not in nanosecond R2PI spectra. Such short S1 lifetimes are common for DNA bases involved in replication and may be nature's defense mechanism to prevent photochemical damage. It is possible that we fail to detect tautomers, such as $1,3,9$, because of a short $\tau^{*}$ but remarkably in the case of xanthine, as opposed to the case of guanine, we do observe the lowest energy tautomer.

\section{Summary}

The R2PI, UV-UV, and IR-UV double resonance spectra of jet-cooled xanthine show that one tautomer is observed under the conditions of our experiment in the spectral range of 36700 to $37700 \mathrm{~cm}^{-1}$. While we cannot rule out other tautomers going unobserved because of different spectral range or short excited state lifetime, current theoretical work suggests one tautomeric form to be significantly more stable in the gas phase than all others which agrees with our experimental results. The ordering of the relative energies obtained via DFT and ab initio calculations suggests that the $\mathrm{N}(7) \mathrm{H}$ tautomer is the most stable one. Based on the calculated vibrational frequencies, the assignment of the IR-UV double resonance spectrum supports the assumption that we indeed observed the $\mathrm{N}(7) \mathrm{H}$ tautomer in the supersonic jet.

Acknowledgement. This material is based upon work supported by the National Science Foundation under Grant No. CHE-0615401. Zsolt Gengeliczki gratefully acknowledges the generous support of the Rosztoczy Foundation. 
Table 1: Calculated vibrational frequencies for the 5 lowest energy tautomers of xanthine in the $\mathrm{N}-\mathrm{H}$ and $\mathrm{O}-\mathrm{H}$ regions. All frequencies have been scaled and given in $\mathrm{cm}^{-1}$. MP2 scaling factor: 0.9422; B3LYP/6-31G(d,p) scaling factor: 0.9613; B3LYP/6-311+G(2d,p) scaling factor: 0.9618 . For comparison, the bands in the experimental IR-UV double resonance spectrum are at 3444,3485 , and $3501 \mathrm{~cm}^{-1}$.

\begin{tabular}{|c|c|c|c|c|}
\hline & MP2/6-31G(d) & B3LYP/6-31G(d,p) & B3LYP/6-311+G(2d,p) & \\
\hline Tautomer & $v / \mathbf{c m}^{-1}$ & $v / \mathbf{c m}^{-1}$ & $v / \mathrm{cm}^{-1}$ & vib. mode \\
\hline \multirow[t]{3}{*}{$\mathrm{X} 1,3,7$} & 3396 & 3484 & 3461 & $\mathrm{~N} 1 \mathrm{H}$ \\
\hline & 3432 & 3514 & 3491 & $\mathrm{~N} 3 \mathrm{H}$ \\
\hline & 3435 & 3525 & 3507 & $\mathrm{~N} 7 \mathrm{H}$ \\
\hline \multirow[t]{3}{*}{ X $1,3,9$} & 3395 & 3482 & 3459 & $\mathrm{~N} 1 \mathrm{H}$ \\
\hline & 3436 & 3516 & 3497 & N3H-N9H \\
\hline & 3437 & 3518 & 3502 & $\mathrm{~N} 3 \mathrm{H}+\mathbf{N 9 H}$ \\
\hline \multirow[t]{3}{*}{$X 1,7,10$} & 3389 & 3475 & & $\mathrm{~N} 1 \mathrm{H}$ \\
\hline & 3434 & 3523 & & $\mathrm{~N} 7 \mathrm{H}$ \\
\hline & 3491 & 3635 & & $\mathrm{O} 10 \mathrm{H}$ \\
\hline \multirow[t]{3}{*}{$X 1,9,10$} & 3387 & 3472 & & $\mathrm{~N} 1 \mathrm{H}$ \\
\hline & 3438 & 3521 & & N9H \\
\hline & 3497 & 3641 & & $\mathrm{O} 10 \mathrm{H}$ \\
\hline \multirow[t]{3}{*}{$X 9,10,11$} & 3443 & 3527 & & N9H \\
\hline & 3458 & 3607 & & $\mathrm{O} 11 \mathrm{H}$ \\
\hline & 3501 & 3646 & & $\mathrm{O} 10 \mathrm{H}$ \\
\hline
\end{tabular}




\section{List of Figures}

Figure 1: The 7 lowest energy xanthine tautomers as calculated at the B3LYP/6$31 \mathrm{G}(\mathrm{d}, \mathrm{p})$ level (blue), MP2/6-31G(d) level (red) and G3 method (black). The relative energy is in units of $\mathrm{kcal} / \mathrm{mol}$. The number scheme for the xanthine tautomer is shown as well.

Figure 2: The R2PI (bottom trace) and UV-UV double resonance (top trace) spectra of xanthine. The UV-UV double resonance spectrum was recorded with the probe laser set at $36741 \mathrm{~cm}^{-1}$.

Figure 3: The IR-UV double resonance (top trace) spectrum of xanthine and the calculated frequencies of the 2 diketo tautomers at the B3LYP/6-311+G(2d,p) level. The bands at 3444,3485 , and $3501 \mathrm{~cm}^{-1}$ are assigned as the $\mathrm{N} 1 \mathrm{H}, \mathrm{N} 3 \mathrm{H}$, and $\mathrm{N} 7 \mathrm{H}$ stretching vibrations respectively.

Figure 4: The IR-UV double resonance spectra of xanthine (black) and its methylated derivatives, 7-methylxanthine (red), and 1,3-dimethylxanthine (blue). 


\section{References}

1 D. T. Hurst, An Introduction to the Chemistry and Biochemistry of Pyrimidines, Purines and Pteridines, Wiley, New York, 1980.

2 S. Miyakawa, H. J. Cleaves and S. L. Miller, Origins of Life and Evolution of the Biosphere, 2002, 32, 209-218.

3 W. Vandervelden and A. W. Schwartz, Geochimica Et Cosmochimica Acta, 1977, 41, 961-968.

4 P. G. Stoks and A. W. Schwartz, Geochimica Et Cosmochimica Acta, 1982, 46, 309-315.

5 A. Abo-Riziq, L. Grace, E. Nir, M. Kabelac, P. Hobza and M. S. de Vries, Proceedings of the National Academy of Sciences of the United States of America, 2005, 102, 20.

6 D. Lichtenberg, F. Bergmann and Z. Neiman, Journal of the Chemical Society COrganic, 1971, 1676-1682.

7 L. F. Cavalieri, J. J. Fox, A. Stone and N. Chang, Journal of the American Chemical Society, 1954, 76, 1119-1122.

8 A. G. Ogston, J. Chem. Soc., 1935, 1376.

9 H. Mizuno, T. Fujiwara and K. I. Tomita, Bulletin of the Chemical Society of Japan, 1969, 42, 3099-\&.

10 P. U. Civcir, Journal of Molecular Structure-Theochem, 2001, 545, 7-15.

11 J. Berdys-Kochanska, J. Kruszewski and P. Skurski, Journal of Physical Chemistry A, 2005, 109, 11407-11412.

12 E. Nir, L. Grace, B. Brauer and M. S. de Vries, Journal of the American Chemical Society, 1999, 121, 4896-4897.

13 E. Nir, C. Janzen, P. Imhof, K. Kleinermanns and M. S. de Vries, Journal of Chemical Physics, 2001, 115, 4604-4611.

14 M. Mons, I. Dimicoli, F. Piuzzi, B. Tardivel and M. Elhanine, Journal of Physical Chemistry A, 2002, 106, 5088-5094.

15 N. J. Kim, G. Jeong, Y. S. Kim, J. Sung, S. K. Kim and Y. D. Park, Journal of Chemical Physics, 2000, 113, 10051-10055.

16 E. Nir, K. Kleinermanns, L. Grace and M. S. de Vries, Journal of Physical Chemistry A, 2001, 105, 5106-5110.

17 C. Plutzer, E. Nir, M. S. de Vries and K. Kleinermanns, Physical Chemistry Chemical Physics, 2001, 3, 5466-5469.

18 G. Meijer, M. S. Devries, H. E. Hunziker and H. R. Wendt, Applied Physics BPhotophysics and Laser Chemistry, 1990, 51, 395-403.

19 M. J. T. Frisch, G. W.; Schlegel, H. B.; Scuseria, G. E.; Robb, M. A.; Cheeseman, J. R.; Montgomery, Jr., J. A.; Vreven, T.; Kudin, K. N.; Burant, J. C.; Millam, J. M.; Iyengar, S. S.; Tomasi, J.; Barone, V.; Mennucci, B.; Cossi, M.; Scalmani, G.; Rega, N.; Petersson, G. A.; Nakatsuji, H.; Hada, M.; Ehara, M.; Toyota, K.; Fukuda, R.; Hasegawa, J.; Ishida, M.; Nakajima, T.; Honda, Y.; Kitao, O.; Nakai, H.; Klene, M.; Li, X.; Knox, J. E.; Hratchian, H. P.; Cross, J. B.; Bakken, V.; Adamo, C.; Jaramillo, J.; Gomperts, R.; Stratmann, R. E.; Yazyev, O.; Austin, A. J.; Cammi, R.; Pomelli, C.; Ochterski, J. W.; Ayala, P. Y.; Morokuma, K.; Voth, G. A.; Salvador, P.; Dannenberg, J. J.; Zakrzewski, V. G.; Dapprich, S.; Daniels, 
A. D.; Strain, M. C.; Farkas, O.; Malick, D. K.; Rabuck, A. D.; Raghavachari, K.; Foresman, J. B.; Ortiz, J. V.; Cui, Q.; Baboul, A. G.; Clifford, S.; Cioslowski, J.; Stefanov, B. B.; Liu, G.; Liashenko, A.; Piskorz, P.; Komaromi, I.; Martin, R. L.; Fox, D. J.; Keith, T.; Al-Laham, M. A.; Peng, C. Y.; Nanayakkara, A.; Challacombe, M.; Gill, P. M. W.; Johnson, B.; Chen, W.; Wong, M. W.;

Gonzalez, C.; and Pople, J. A., Gaussian 03, Revision C.02, in Gaussian, Inc., Wallingford CT, 2004.

20 A. D. Becke, J. Chem. Phys., 1993, 98, 5648.

21 C. Lee, W. Yang and R. G. Parr, Phys. Rev. B, 1988, 37, 785.

22 B. Miehlich, A. Savin, H. Stoll and H. Preuss, Chem. Phys. Lett., 1989, 157, 200.

23 C. Moller and M. S. Plesset, Phys. Rev., 1934, 46, 618-622.

24 M. Head-Gordon, J. A. Pople and M. J. Frisch, 1988, 153, 503.

25 M. J. Frisch, M. Head-Gordon and J. A. Pople, Chem. Phys. Lett., 1990, 166, 275.

26 M. J. Frisch, M. Head-Gordon and J. A. Pople, Chem. Phys. Lett., 1990, 166, 281.

27 M. Head-Gordon and T. Head-Gordon, Chem. Phys. Lett., 1994, 220, 122.

28 S. Saebo and J. Almlof, Chem. Phys. Lett., 1989, 154, 83.

29 J. B. Foresman, and A. Frisch. . ed. Gaussian, Pittsburgh, PA, 1996.

30 A. P. Scott, Radom, L., J. Phys. Chem., 1996, 100, 16502-16513.

31 A. D. M. a. G. S. Chandler, J. Chem. Phys., 1980, 72, 5639-5648.

32 J. S. B. R. Krishnan, R. Seeger, and J. A. Pople, J. Chem. Phys., 1980, 72, 650654.

33 K. R. L. A. Curtiss, P. C. Redfern, V. Rassolov, and J. A. Pople, J. Chem Phys., 1998, 109, 7764-7776.

34 N. S. Hush and A. S. Cheung, Chemical Physics Letters, 1975, 34, 11-13.

35 W. L. a. D. R. H. S. K. Kim, J. Phys. Chem., 100, 7933 -7937.

36 P. U. M. P. Andersson, Journal of Physical Chemistry A, 2005, 109, 2937-2941.

37 A. Broo, J. Phys. Chem. A, 1998, 102, 526-531.

38 C. B. Crespo-Hernandez C.E., Hare P.M., Kohler B., Chem. Rev., 2004, 104, 1977-2019.

39 D. W. Sobolewski A.L., Hattig C., Proc. Natl. Acad. Sci. USA, 2005, 102, 1790317906. 